\title{
Does the Prefrontal Cortex Play an Essential Role in Consciousness? Insights from Intracranial Electrical Stimulation of the Human Brain
}

\author{
${ }^{\circledR}$ Omri Raccah, ${ }^{1}{ }^{\circledR}$ Ned Block, ${ }^{2}$ and ${ }^{\circledR}$ Kieran C.R. Fox ${ }^{3,4}$ \\ ${ }^{1}$ Department of Psychology, New York University, New York, New York 10003, ${ }^{2}$ Department of Philosophy, New York University, New York, New \\ York 10003, ${ }^{3}$ Department of Neurology \& Neurological Sciences, Stanford University, Stanford, California 94305, and ${ }^{4}$ School of Medicine, Stanford \\ University, Stanford, California 94305
}

\begin{abstract}
A central debate in philosophy and neuroscience pertains to whether PFC activity plays an essential role in the neural basis of consciousness. Neuroimaging and electrophysiology studies have revealed that the contents of conscious perceptual experience can be successfully decoded from PFC activity, but these findings might be confounded by postperceptual cognitive processes, such as thinking, reasoning, and decision-making, that are not necessary for consciousness. To clarify the involvement of the PFC in consciousness, we present a synthesis of research that has used intracranial electrical stimulation (iES) for the causal modulation of neural activity in the human PFC. This research provides compelling evidence that iES of only certain prefrontal regions (i.e., orbitofrontal cortex and anterior cingulate cortex) reliably perturbs conscious experience. Conversely, stimulation of anterolateral prefrontal sites, often considered crucial in higher-order and global workspace theories of consciousness, seldom elicits any reportable alterations in consciousness. Furthermore, the wide variety of iES-elicited effects in the PFC (e.g., emotions, thoughts, and olfactory and visual hallucinations) exhibits no clear relation to the immediate environment. Therefore, there is no evidence for the kinds of alterations in ongoing perceptual experience that would be predicted by higher-order or global workspace theories. Nevertheless, effects in the orbitofrontal and anterior cingulate cortices suggest a specific role for these PFC subregions in supporting emotional aspects of conscious experience. Overall, this evidence presents a challenge for higher-order and global workspace theories, which commonly point to the PFC as the basis for conscious perception based on correlative and possibly confounded information.
\end{abstract}

\section{Introduction}

Many neuroscientists, philosophers, and psychologists interested in the problem of consciousness are now focused on deciphering its neural basis (Crick and Koch, 1990; Chalmers, 2000). This debate generally defines consciousness in terms of conscious experience, or "what it is like" to have an experience (often called phenomenal consciousness) (Nagel, 1974; Block, 1995; Chalmers, 1996), and we follow this sense here. The past decade has seen a large number of studies focused on uncovering what role, if any, activity in the human PFC plays in phenomenal consciousness (Michel and Morales,

\footnotetext{
Received July 22, 2020; revised Dec. 22, 2020; accepted Dec. 23, 2020.

Author contributions: 0.R. conceived of the project; 0.R., N.B., and K.C.R.F. contributed to the formulation and writing of the manuscript.

This work was supported by National Science Foundation Graduate Research Fellowship DGE 1839302 to 0. R., and Stanford University School of Medicine Medical Scholars Research Fellowship to K.C.R.F. We thank Richard Brown, Luke Huszar, Aaron Kucyi, Christof Koch, Barbara Montero, Matthias Michel, Rafi Malach, David Poeppel, Josef Parvizi, Moshik Raccah, and Leor Zmigrod for comments on an earlier version of the manuscript.

The authors declare no competing financial interests.

Correspondence should be addressed to Omri Raccah at or409@nyu.edu.

https://doi.org/10.1523/JNEUROSCl.1141-20.2020

Copyright $\odot 2021$ the authors
}

2020). Most proponents of PFC involvement in conscious experience subscribe to either higher-order or global workspace theories (Baars, 1993; Dehaene, 2014; Brown et al., 2019; Lau, 2019; Cleeremans et al., 2020; Mashour et al., 2020). Under these frameworks, perceptual content must be re-represented or maintained in association regions involved in cognitive processing to reach consciousness; these theories therefore endorse an essential role for the PFC in consciousness.

On the other side are those who endorse first-order recurrent activation theories of consciousness (Silvanto et al., 2005; Lamme, 2014; Billeke et al., 2017; Block, 2019). These theorists argue that the PFC is neither necessary nor sufficient for consciousness, but rather that conscious contents are determined locally in sensory systems. The key difference between these views hinges on whether local sensory processing is sufficient for conscious perception, or whether unconscious sensory contents require interaction or other involvement with "higher" cognitive systems for conscious experience to arise. The PFC has therefore become the central focus of these debates because of its established roles in attention, working memory, and other complex cognitive functions (Boly et al., 2017; Odegaard et al., 2017). 
It is important to distinguish between the neural constitution of consciousness and contingent global enabling factors of consciousness (Boly et al., 2017). For example, blood flow enables conscious processing but does not constitute it (but see Moore and Cao, 2008). Therefore, advocates of first-order recurrent activation can allow that PFC activity may control arousal, thus enabling sensory cortices to be activated, yet nonetheless argue that PFC activity is not constitutive of consciousness. Similarly, proponents of prefrontal involvement can allow that, without sensory input, there would be no perceptual consciousness, yet argue that only PFC activity plays a constitutive role. Throughout this Viewpoints article, we are concerned with the neural constitution of consciousness, not the enabling conditions.

Neuroimaging studies showing increased prefrontal engagement during conscious sensory processing have provided primary empirical evidence in favor of prefrontal involvement in consciousness (Lau and Passingham, 2006; Dehaene and Changeux, 2011). Furthermore, several compelling studies have successfully decoded the contents of conscious perception from activity in the monkey PFC during binocular rivalry and flash suppression tasks, in which perception is not dependent on the stimulus (Panagiotaropoulos et al., 2012, 2020; Safavi et al., 2014; Kapoor et al., 2018, 2019, 2020). However, it has been claimed that these findings might be confounded by postperceptual, cognitive processes related to sensory content (e.g., thinking or reasoning about the stimulus), which may not be necessary for conscious experience (Block, 2019, 2020). Whether or not the PFC plays an essential role in consciousness therefore remains intensely debated, and current methods in human neuroscience, which are almost exclusively correlational in nature, seem unable to resolve the controversy (Boly et al., 2017; Odegaard et al., 2017).

In this Viewpoints article, we synthesize a crucial body of evidence that can help clarify the role of the PFC in consciousness, but which has been largely overlooked by both proponents and opponents of prefrontal theories: namely, perturbations of conscious experience elicited by intracranial electrical stimulation (iES) of the PFC in awake neurosurgical patients (for readers unfamiliar with the method, we provide a brief overview in Box 1). Despite its limitations, iES provides probably the best means of causally perturbing brain function in humans, and iES throughout the brain has long been known to cause radical, yet replicable, changes in conscious experience (for comprehensive reviews, see Selimbeyoglu and Parvizi, 2010; Desmurget et al., 2013). The causal information afforded by iES could provide critical evidence regarding whether activity in the PFC reflects conscious percepts that are based in the PFC or, alternatively, are byproducts of conscious states based in other parts of the cerebral cortex (or even subcortical regions).

Although iES has been used in patients with brain disease for more than a century (Borchers et al., 2012), reports of iES of the frontal lobe are relatively rare and are scattered throughout a vast and little-known literature. In an effort to inform the debate regarding consciousness and the PFC, we present a concise review of studies probing changes in conscious experience caused by iES of the human PFC. Our synthesis of the available data reveals a complex picture that does not provide unequivocal support for either theoretical viewpoint: we find that iES-elicited effects in the PFC are rare, highly specific, and largely confined to particular subregions, such as the ACC and orbitofrontal cortex (OFC). In contrast, stimulation of the anterolateral $\mathrm{PFC}$ regions that figure most prominently in prefrontal theories of consciousness seldom elicits changes in conscious experience.
Box 1. iES: a brief overview of the method's strengths and limitations. iES is typically used in epileptic patients implanted with tens to hundreds of electrode contacts to precisely localize the source of medication-resistant seizures. Electrode grids placed on the surface of the cortex, or depth probes penetrating into deep subcortical structures, can be used (Fig. 1). These electrode contacts passively record population neuronal activity but can also be used to deliver current to stimulate specific neuronal populations during the iES procedure (Parvizi and Kastner, 2018). Typically, bipolar stimulation (across two adjacent electrodes) is administered at $50 \mathrm{~Hz}$ and between 2 and $10 \mathrm{~mA}$, in line with an empirically derived safe window (Gordon et al., 1990). Sham stimulation is used to control for demand characteristics, especially when meaningful or intense experiences are reported, and has proven to be a very effective control (Fox and Parvizi, 2021; Fox et al., 2020). Following each iES stimulation (or sham), the patient is asked standardized, open-ended questions about whether any effect was elicited (e.g., "Did you experience any change?"), with follow-up questions as needed to clarify the specific effects.

This approach has revealed a striking variety of effects on conscious experience depending on the brain region stimulated. For instance, iES of the medial temporal lobe can elicit detailed episodic memories and hallucinatory, dream-like experiences (Curot et al., 2017); iES of faceselective areas of the fusiform gyrus produces marked and selective changes in conscious face perception (Parvizi et al., 2012; Rangarajan et al., 2014; Keller et al., 2017; Schrouff et al., 2020); and stimulation of unimodal regions generally elicits simple effects in the corresponding sensory modality, such as perception of phosphenes, shapes, and colors following iES of the occipital lobe (Selimbeyoglu and Parvizi, 2010; Winawer and Parvizi, 2016; Bosking et al., 2018). The variety of elicited effects is seemingly limitless and also includes laughter (Fried et al., 1998), pain (Mazzola et al., 2012), and even gross alterations of self-awareness ("out-of-body" experiences) (Blanke et al., 2002). Importantly, even high-level, nonperceptual effects can be evoked, such as the intention to move (Desmurget et al., 2009) or a strong will to persevere in the face of imminent challenges (Parvizi et al., 2013).

While iES is a powerful causal method for investigating human brain function (Desmurget et al., 2013), its various limitations also need to be acknowledged. On the subjective side, patients might underreport subtle effects (false negatives), or overreport effects due either to demand characteristics (Nichols and Maner, 2008) or to confusion of ongoing spontaneous thoughts with iES-elicited effects (false positives). Many striking case studies have demonstrated, however, that patients are eloquent and determined reporters of even nuanced and complex iES-elicited effects (e.g., Blanke et al., 2002; Desmurget et al., 2009; Parvizi et al., 2013), greatly mitigating the concern over false negatives. Moreover, quantitative assessment of first-person reports following sham stimulation has shown that false positives are indeed extremely rare. Patients almost never report effects following sham trials, suggesting that demand characteristics are minimal and also that patients reliably distinguish between their ongoing spontaneous mentation and any 
experiences elicited by iES (Fox and Parvizi, 2021; Fox et al., 2020).

On the neurophysiological side, the effects of injecting electrical current into living brain tissue are poorly understood (Rattay, 1999; Tehovnik et al., 2006; Winawer and Parvizi, 2016). At the neuronal level, whether iES induces excitation, inhibition, or some mix of both remains unclear. Little is known about the degree to which current spreads beyond the stimulating electrode site, either passively through volume conduction or actively through neuronal signal propagation. Further, there is wide variability in the stimulation parameters and electrode types used by different research groups, and the busy inpatient hospital setting of iES research seldom allows for a comprehensive exploration of this parameter space. This is critical because the effects elicited by iES are known to vary with the frequency and amplitude of stimulation (Mohan et al., 2020), with higher parameter values tending to elicit more potent responses across many domains, including visual (Winawer and Parvizi, 2016; Bosking et al., 2017), physiological (Inman et al., 2018), and emotional effects (Yih et al., 2019). Additionally, research throughout the early-tomid 20th century tended to use monopolar stimulation (as do most DBS interventions today), whereas bipolar stimulation is the standard in most contemporary iES functional mapping sessions. To our knowledge, the consequences of such differences (if any) have never been systematically explored. Finally, even when standardized stimulation parameters are used, differences in the particular tissue being stimulated need to be considered. Regions throughout the brain exhibit high variability in local synaptic connectivity, cytoarchitecture, and broader functional-anatomic network properties. These specific properties almost certainly interact with iES pulses, influencing their reception and propagation in a given type of brain tissue, and ultimately their effect (if any) on behavior and subjective experience (Fox et al., 2020).

A broader concern is that the brains being investigated all belong to patients with severe neurologic disease of some kind (usually epilepsy, but also brain tumors and, increasingly, medication-resistant psychiatric illness). In addition to any inherent pathologic activity or anatomy, chronic neurologic and psychiatric illness likely lead to compensatory neuroplastic changes at both the functional and structural level (Sutula, 2004; Ketzef et al., 2011; Mole et al., 2016). The extent of the alterations to normal neurophysiological function induced by both pathology and plasticity in severe epilepsy is not precisely known. Nonetheless, recent work has found that pathologic epileptic brain tissue indeed shows normal stimulusevoked responses when seizures are not occurring ( $S$. Liu and Parvizi, 2019). These responses are indistinguishable from those elicited in healthy (i.e., nonepileptic) brain tissue distant from the seizure focus (S. Liu and Parvizi, 2019). Yet because of the unavoidable absence of normal controls, concerns over whether iES and other intracranial EEG data are generalizable to healthy human brains will always linger. All the many caveats listed above should be kept in mind when interpreting and drawing inferences from the empirical iES literature.

\section{What would various theories of consciousness predict the effects of iES within the PFC to be?}

Before considering the empirical data, it is crucial to have some idea of what various models of the neural basis of consciousness would predict to happen when PFC activity is modulated with iES. Most models have not explicitly addressed or included iES data (hence the present Viewpoints article); therefore, specific predictions are generally lacking from theoretical accounts. While we do not wish to commit other researchers to any specific hypotheses they have not explicitly endorsed, we nonetheless provide a brief overview of what we believe various theories should and would predict to be the effect of iES to the PFC.

Higher-order (or "cognitivist") theories have proposed various ways in which perceptual representations might interact with, or be instantiated in, PFC activity (Lau and Rosenthal, 2011; Brown, 2015), which we divide into two general types. In one version of higher-order theories, the "double representation" model, the perceptual contents of conscious experience are represented in the PFC as well as sensory cortices (Lau and Rosenthal, 2011; Brown, 2015). According to this model, the content of the PFC representation at least partly determines the conscious content (Rosenthal, 2011). If this view is correct, then iES to the PFC should perturb the perceptions that patients are currently experiencing. For example, stimulation in a patient who is visually aware of the doctor's face is expected to result in an alteration related to the face (e.g., distortion of facial features). In the other version of higher-order theories, known as "perceptual reality monitoring," percepts are not directly re-represented or duplicated in the PFC, but rather PFC representations are thought of as indexes or pointers that refer to particular perceptual content in sensory cortices (Lau, 2019; Cleeremans et al., 2020). The contents of the pointers are thought to indicate whether the perceptual content is likely to reflect the world accurately. According to this view, iES to the PFC may result in indexing of different sensory content (making a previously unconscious first-order representation conscious) or it might disrupt this monitoring process altogether. Again, based on this indexing or pointer view, stimulation would be predicted to change ongoing perceptual experience, but it would not be expected to produce entirely novel experiences unrelated to ongoing conscious perception (i.e., hallucinations or imagined experiences).

In the case of global workspace theories, PFC activity is thought to be involved in maintaining and broadcasting specific perceptual contents (Mashour et al., 2020). For example, when a participant is conscious of a face, perhaps by virtue of activity in the fusiform face area, this content is maintained by a neural coalition involving the lateral PFC. This framework should therefore predict that iES to the PFC will alter or impede global broadcasting or perhaps change the content that is globally broadcast. Again, we would expect an alteration or disruption in ongoing perception, but not outright hallucination. In summary, all higher-order and global workspace views argue that PFC plays a constitutive role in consciousness; consequently, all should predict some sort of alteration of ongoing conscious experience in patients following iES of the PFC.

Noncognitivist theories of consciousness (e.g., recurrent activation theories) (Silvanto et al., 2005; Lamme, 2014; Billeke et al., 2017) should generally predict no changes in ongoing perceptual experience following PFC stimulation, except to the extent that PFC activation affects arousal level or other enabling conditions of conscious experience. However, noncognitive approaches do 
A

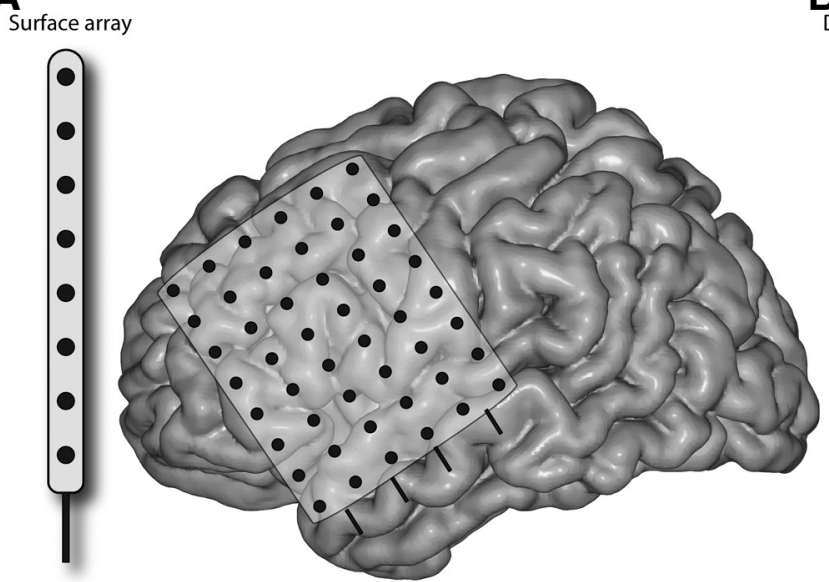

B

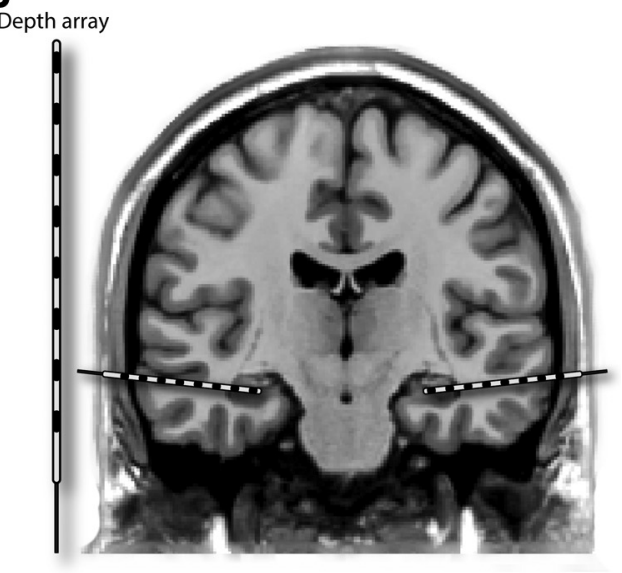

Figure 1. iES of the human brain via two common approaches. $\boldsymbol{A}$, Electrocorticography uses strips or grids of electrodes implanted subdurally on the surface of the cortex. $\boldsymbol{B}$, Stereo-EEG uses penetrating depth electrode arrays following stereotactic coordinates to target deeper brain structures. Modified with permission from Fox et al. (2018a).

allow for conscious aspects of conceptual thought and other cognitive processes (which are generally consistent with, and specific to, the acknowledged functional roles played by the PFC) to be based in PFC (Block, 2019). Therefore, insofar as conceptual thought or other cognitive processes have phenomenal qualities and are based in the PFC, perturbations in these contents of conscious experience do not provide unequivocal support for either side of the debate. Information integration theories of consciousness, such as IIT (Tononi et al., 2016), do not rule out a role for the PFC in consciousness, but they argue that the local connectivity patterns found in the PFC are not well suited for integrating information. Information integration theory should therefore predict relatively few changes in conscious experience following stimulation to PFC subareas relative to iES of more posterior sensory areas.

\section{Changes in conscious experience elicited by iES of human PFC}

The PFC comprises a large portion of the cortical mantle. Although definitions vary, standard anatomic demarcations of the PFC exclude motor regions of the frontal lobe but include all more anterior areas (i.e., Brodmann areas 8-14 and 44-47, as well as aspects of the cingulate gyrus, including areas 24, 25, and 32; Fig. 2) (Carlén, 2017; Dixon et al., 2017). Significant functional heterogeneity is apparent across and within these distinct anatomic subareas (Dunbar and Sussman, 1995; Miller and Cohen, 2001).

\section{Situating the PFC within a whole-brain gradient of $i E S$-elicited effects}

Although legendary neurosurgeon Wilder Penfield reported eliciting an incredible variety of effects throughout the human brain, he never reported any nonmotor effects in PFC regions (Penfield and Boldrey, 1937; Feindel and Penfield, 1954; Penfield, 1958; Mullan and Penfield, 1959; Penfield and Perot, 1963). Consistent with Penfield's findings, lesion studies from a century of neurosurgery research show that areas of the PFC can be removed with little apparent change in conscious experience to the patient, whereas lesions in primary motor or sensory areas (often referred to as eloquent cortex) cause striking differences in content-specific perceptual experience (Henri-Bhargava et al., 2018; Koch, 2019).
The apparent rarity of reports of conscious changes following iES of the PFC raises the question of just how rare these effects really are relative to the rest of the cortex. A recent study we conducted shed light on this question (Fox et al., 2020). We analyzed iES-elicited effects across 67 neurosurgical patients and 1537 electrode sites covering the entire cerebral cortex, exploring the probability that $\mathrm{iES}$ would elicit effects across all cortical regions in the human brain. We found a global gradient in the rate of elicited perceptible effects (which we refer to as elicitation rate), with the highest chance $(\sim 67 \%)$ of eliciting an effect in unimodal regions, such as the primary visual cortex. Conversely, stimulation of the most anterior PFC regions (both medial and lateral) yielded the lowest elicitation rates in the entire brain (Fig. 3). Effects were sometimes observed in particular PFC subregions, however, such as the OFC and ACC. This study provided a large-scale, quantitative confirmation of a conclusion already evident from qualitative assessments of the iES literature (Penfield and Perot, 1963; Selimbeyoglu and Parvizi, 2010): stimulation of the most anterior aspects of the PFC (whether medial or lateral) almost never affects conscious experience. These findings corroborate those of a recent study showing only null results in sensory phenomenology in a large cohort of 36 patients in whom various medial PFC regions were stimulated (compare Trevisi et al., 2018, their Fig. 2). Nonetheless, occasional exceptions to this general trend have been reported in isolated case studies (Blanke et al., 2000; Vignal et al., 2000; Vaca et al., 2011; Popa et al., 2016; A. Liu et al., 2020), and the details of effects elicited in the OFC and ACC are also of considerable interest. The subsequent sections explore evidence for iES-elicited effects in various PFC subregions in detail.

\section{Effects following iES of the lateral PFC}

Conscious visual perception is studied using "masking" paradigms, the attentional blink, continuous flash suppression, and other techniques (Kim and Blake, 2005; Tsuchiya and Koch, 2005; Breitmeyer et al., 2006; Yang et al., 2014), which render target stimuli subjectively imperceptible. Numerous neuroimaging studies have shown that reported versus unreported visual perception is associated with differences in activation in the dorsolateral PFC (DLPFC) (Lau and Passingham, 2006; Dehaene and Changeux, 2011). Higher-order and global workspace theories have implicated the lateral PFC in conscious perception on the basis of these findings. In a notable example, Lau and Rosenthal 

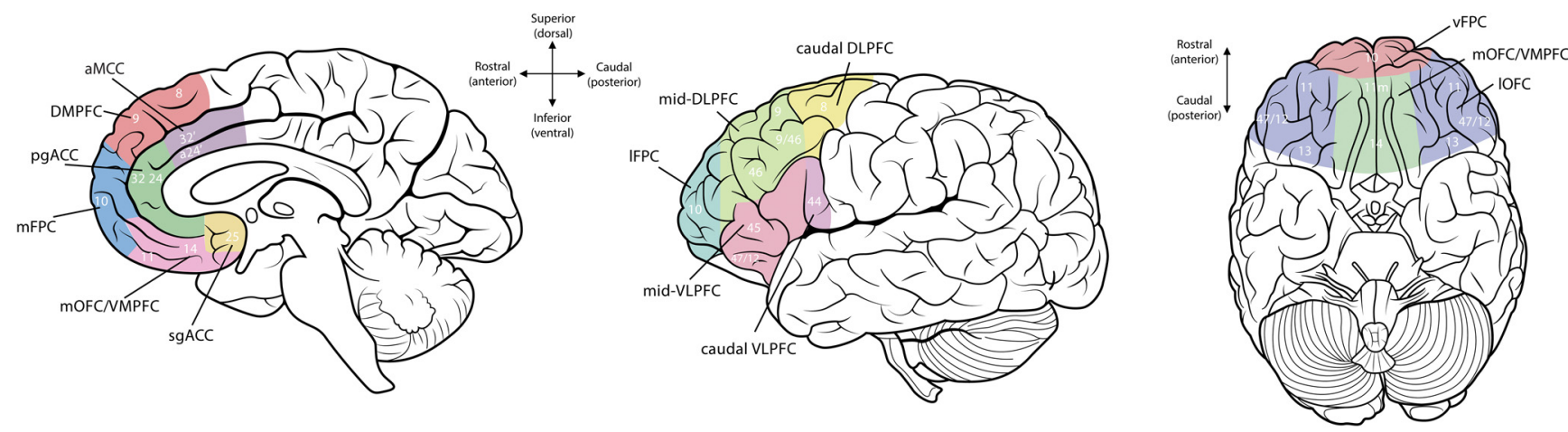

Figure 2. Anatomical parcellation of the human PFC. PFC regional delineation based on prior anatomic and neuroimaging studies. sgACC, Subgenual ACC; pgACC, pregenual ACC; aMCC, anterior mid-cingulate cortex; IOFC, lateral OFC; $\mathrm{mOFC}$, medial OFC; IFPC, lateral frontopolar cortex; mFPC, medial frontopolar cortex; vFPC, ventral frontopolar cortex; DMPFC, dorsomedial PFC.

(2011) proposed a higher-order model of visual consciousness in which sensory information originating in the occipital lobe is rendered conscious when re-represented in the DLPFC as well as lateral frontopolar cortex (i.e., Brodmann area 10; Fig. 2). This model focuses specifically on visual consciousness, but recent variants of higher-order theories have implicated the DLPFC and frontopolar cortex in emotional consciousness as well (LeDoux and Brown, 2017; LeDoux, 2020a). Furthermore, such models have recently been expanded to accommodate other sensory modalities by incorporating the ventrolateral PFC (VLPFC) (Jack and Shallice, 2001; Brown et al., 2019). The lateral PFC, broadly defined, has therefore become a central focus for proponents of prefrontal involvement in consciousness.

Despite widespread reports of null effects following iES of the PFC (Penfield and Perot, 1963; Selimbeyoglu and Parvizi, 2010; Fox et al., 2020), spontaneous epileptic discharges in the PFC have occasionally been noted to induce visual perceptual experiences (Bancaud and Talairach, 1992; Chauvel et al., 1995; Manfioli et al., 2013). Furthermore, the PFC displays ample anatomic connections to temporal lobe structures which, when stimulated, yield a wide range of often intense effects (Selimbeyoglu and Parvizi, 2010; Curot et al., 2017). Building on similar evidence, Blanke et al. (2000) administered iES in the left lateral PFC of 2 patients. In Patient 1 , the authors reported complex visual hallucinations produced by stimulating two adjacent electrodes located in the VLPFC. The patient reported: "All of a sudden it seems as if many things are coming at me, I can hardly see them [...] at the same time, a church, a castle, a big room." Following stimulation of a neighboring site, the patient reported: "It seems to me as if a lot of thoughts are coming, but it seems to me as if I do not have the time to retain them all." In Patient 2, stimulation of the posterior aspect of the DLPFC, directly anterior to the frontal eye fields (Fig. 4), similarly elicited an immersive, hallucinatory visual experience. The patient described the "presence" of a young man in the room adjoining her own, as well as details of the man's clothing and physical appearance. The authors concluded that iES of DLPFC and VLPFC could elicit immersive visual experiences similar to the episodic and dream-like experiences usually only reported following iES of the temporal lobe (Curot et al., 2017), although they acknowledged that the reported effects could be understood as perturbation of ongoing, conceptual thought processes rather than visual hallucinations per se.

The notion that the elicited experiences might instead be more abstract and conceptual in nature is suggested by Patient 1 reporting "thoughts coming all at once," as well as Patient 2 describing the elicited experience as akin to "an idea or thought."
However, the authors pointed to prior evidence that spontaneous epileptic auras characterized by conceptual thoughts tend to involve recurrent and specific thought content (e.g., a particular word or phrase) (Mendez et al., 1996) and are often accompanied by speech impediments (Penfield, 1972; Mendez et al., 1996), neither of which were observed in these cases. Moreover, patients suffering from intrusive conceptual thoughts generally report no alteration in perceptual experience. Blanke et al. (2000) therefore concluded that the observed effects more likely reflected changes in visual experience, rather than conceptual or abstract thoughts.

Importantly, this interpretation is challenged by recent evidence showing that stimulation at comparable anatomic sites in the left DLPFC and VLPFC yielded marked changes in thought content without any reported changes in perceptual experience (A. Liu et al., 2020). A. Liu et al. (2020) described 3 patients who reported conceptual thoughts following lateral PFC stimulation (Fig. 4). For instance, 1 patient reported conceptual thoughts following stimulation to the left VLPFC: "I had a thought about a game that kids play in the summer, I can't think of the exact game." In another patient, stimulation of the left DLPFC and middle frontal gyrus elicited thoughts about "a person." In contrast to the reports by Blanke et al. (2000), the patient was not able to describe the person's physical characteristics and confirmed that the experience was not visual in nature. Lastly, in another patient, the authors reported "complex auditory phenomena" following stimulation to a posterior VLPFC site. However, similar effects were reported in the neighboring electrode pairs in the superior temporal gurus, suggesting that this isolated effect may be because of the close anatomic proximity of auditory regions in the temporal lobe.

In another study, Popa et al. (2016) reported 1 patient in whom stimulation to the DLPFC produced similar reports of conceptual thought following stimulation, as well as 2 patients in whom iES of white matter underlying the posterolateral PFC caused reportable changes in thought content. While effects following stimulation of white-matter pathways should be interpreted with caution, Popa et al. (2016) nonetheless provide further confirmation of the rarity of changes in conscious content following iES to posterior subregions of the lateral PFC and the extent to which these rare elicited experiences are devoid of perceptual content.

In a notable case study, Vignal et al. (2000) reported a patient in whom iES of the right VLPFC (Fig. 4) consistently caused face-related visual hallucinations across two stimulation sessions. For instance, the patient reported: "I see many faces appear... there was one with glasses, others with hats." When viewing the doctor's face, the patient reported "it is as if your face was 


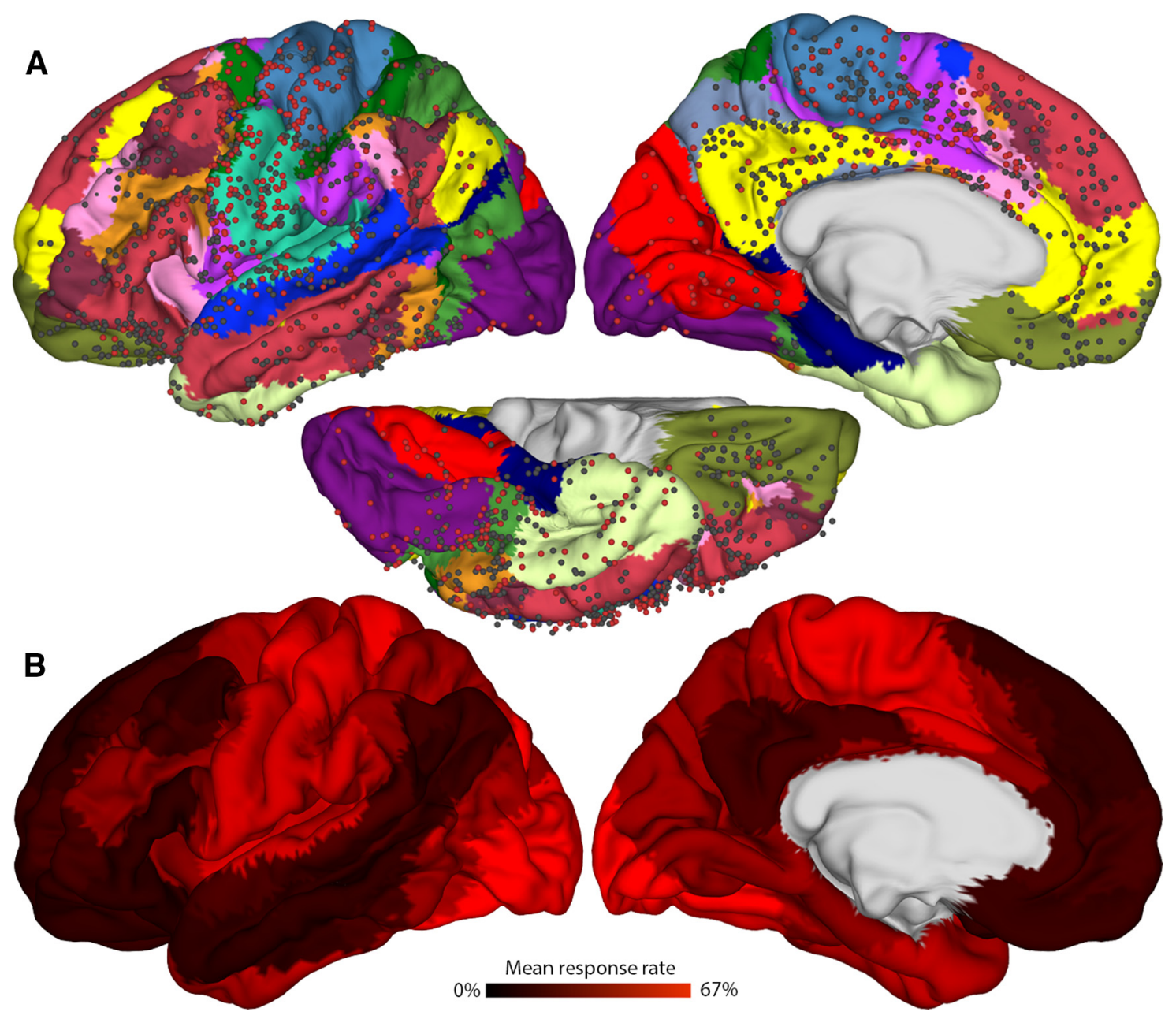

Figure 3. Mean elicitation rate across the entire cerebral cortex as a function of iES. The mean elicitation rate across 67 participants (1537 electrode sites) projected onto a standardized brain template. $\boldsymbol{A}$, Red circles represent electrode sites where stimulation induced a change in conscious experience or evoked motor responses (of which the patient was also consciously aware). Black circles represent "null" electrode sites where no effects of any kind were elicited, even with repeated high-amplitude stimulation. Distinct colors represent 17 individual largescale brain networks based on resting-state fMRI connectivity and clustering analysis (Yeo et al., 2011). B, Mean elicitation rate within individual brain networks. The highest response rates are in somatomotor and visual networks, whereas default, limbic and other transmodal networks show the lowest elicitation rates. Reproduced with permission from Fox et al. (2020).

transformed, one time without glasses, once with a hat, but always the same face" and "it was as if you changed your face, that it was remodeled and that it became another face and so forth." Although this case study is intriguing, the patient reported similar face hallucination experiences while looking at the doctor's lab coat before looking at the doctor's face and the patient refers back to those hallucinations, saying "many faces again" (emphasis added). Therefore, it is not entirely clear whether this effect was a hallucination or a perturbation of ongoing perception. If the latter, then to our knowledge, this is the only case of perturbation of ongoing perceptual experience ever reported following $\mathrm{iES}$ to the lateral PFC.

Finally, Vaca et al. (2011) reported a single case in which stimulation of the posterior VLPFC repeatedly induced a sensation of mirth along with laughter. As far as we are aware, no similar mirth sensations (alone or with laughter) have ever been reported following iES to the lateral PFC, before or since, although such effects have been reported in the supplementary motor area (Fried et al., 1998) and the ventral temporal cortex (Arroyo et al., 1993; Satow et al., 2003).

These studies (Blanke et al., 2000; Vignal et al., 2000; Vaca et al., 2011; Popa et al., 2016; A. Liu et al., 2020) represent, to our knowledge, the only published reports of iES-elicited effects in lateral PFC regions (not counting motor effects in various frontal motor areas). The sparsity of research reports, the small number of participants, and the general lack of consistent findings to date mean that these effects need to be treated with considerable caution. It is also notable that these responsive electrode sites were always in the more posterior parts of the lateral PFC (Fig. 4). To our knowledge, iES-elicited effects in frontopolar cortex (whether medial, lateral, or ventral) have never been reported in the literature (Fig. 4). And as noted above, a recent study we conducted with a large cohort of iES patients ( $n=67)$ likewise found exclusively null effects in frontopolar cortex (Fox et al., 2020).

\section{Effects following iES of the anteromedial PFC}

Relative to other PFC subregions, such as the OFC, ACC, and lateral PFC (Dehaene and Changeux, 2011; Brown et al., 2019), anteromedial prefrontal regions (i.e., Brodmann areas $9 \mathrm{~m}$ and $10 \mathrm{~m}$ ) have received little attention in neural models of consciousness. We are not aware of any past research that reports iESinduced phenomenal changes in these regions (Selimbeyoglu and Parvizi, 2010), and recent work across dozens of patients, from both our own group (Fox et al., 2020) and others (Trevisi et al., 2018), indicates only null results in these areas. 
Effects following iES of the OFC

To date, proponents of PFC involvement in consciousness have primarily focused on the role of the lateral PFC in visual consciousness. Nevertheless, several models also include the OFC as a locus for integrating multimodal perceptual, cognitive, and emotional experience (Baylis et al., 1995; Cavada et al., 2000; Brown et al., 2019). Under higher-order theories, the OFC has been theorized to either generate so-called "first-order" (nonconscious) information, which is then rendered conscious through interaction with the lateral PFC, or to itself serve to enable conscious experience (Brown et al., 2019). Despite the clear importance of this region to higher-order processes, such as personality and the sense of self (Kringelbach and Rolls, 2004; Northoff et al., 2006), remarkably few studies in more than a century of such research have reported effects of iES to the OFC (Selimbeyoglu and Parvizi, 2010). Occasional case studies of iES of the OFC have reported tingling sensations and muscle twitching (Begum et al., 2006), as well as epigastric and retrosternal sensations (Mulak et al., 2008). Intriguingly, in an early study, Mahl et al. (1964) reported memory recall, hallucinations, illusions, and even changes in personality following OFC stimulation in a single patient, but these effects were never replicated in a larger cohort or with modern electrode localization procedures.

Recently, we conducted a more comprehensive study (Fox et al., 2018b), with iES applied in the OFC of 22 epilepsy patients. Across patients and 172 unique stimulation sites, OFC stimulation produced vivid reports of olfactory, gustatory, somatosensory, and multimodal (combined smell and taste) perceptual experiences. Changes in visual experience, however, were never reported. We also showed that elicited perceptual experience was often coupled with emotion (e.g., aversive smells or pleasant tastes), although "pure" emotional experience, devoid of sensory content (e.g., "sadness"), was also occasionally reported. Importantly, despite the diverse and often complex changes reported, effects were nonetheless very rare overall: stimulation of $83 \%$ of electrodes never yielded any effects whatsoever. This low elicitation rate (17\%) is in marked contrast to unimodal brain regions, where positive response rates can reach 67\% (Fox et al., 2020). Moreover, an anterior-posterior gradient was observed, such that the middle and posterior parts of OFC showed the highest rate of effects, whereas the most anterior OFC sites (i.e., the ventral frontal pole, BA 10) showed a complete absence of effects (compare Fox et al., 2018b, their Fig. 1).

In general agreement with these findings, recent work by Rao et al. (2018) showed that iES of the lateral OFC caused improvements in mood in patients with moderate to severe trait depression, whereas $\mathrm{iES}$ of medial OFC had no significant effect. Stimulation of the ACC produced analogous improvements in mood, although with less consistency than stimulation of OFC. This study provided further confirmation that stimulation of specific PFC subregions can result in high-level changes in conscious experience, such as alterations of mood.

\section{Effects following iES of the ACC}

The ACC has been implicated in a variety of "higher" cognitive functions, including emotional monitoring, attention allocation, and reward-based decision-making (Devinsky et al., 1995; Lane et al., 1998; Bush et al., 2002), and has received considerable attention from proponents of prefrontal involvement in consciousness. Consistent with a role for the ACC in consciousness, neuroimaging studies coupled with masking paradigms have shown greater ACC activation associated with reported relative to unreported processing of visual (Dehaene et al., 2001; Gross et al., 2004; Sergent et al., 2005; Van Gaal et al., 2011), auditory (Sadaghiani et al., 2009), and even somatosensory stimuli (Boly et al., 2007). Global workspace theorists have also pointed out that the high density of long-range excitatory pyramidal neurons found in the ACC could plausibly serve as a substrate for a highly integrative function, such as consciousness (Dehaene and Changeux, 2011; Mashour et al., 2020). Recent accounts of higher-order theories (LeDoux and Brown, 2017; Brown et al., 2019; LeDoux, 2020a) have suggested that the ACC (like the $\mathrm{OFC}$ ) contributes to more complex aspects of phenomenal consciousness (e.g., emotions, memories, sense of self, and so on), either independently or via interactions with the lateral PFC (LeDoux and Brown, 2017; Brown et al., 2019; LeDoux, 2020a).

$\mathrm{iES}$ of the ACC has resulted in intriguing reports of the urge to move (Kremer et al., 2001) and to laugh (Chassagnon et al., 2008), as well as the actual motor expression of laughter and smiling (Sperli et al., 2006). ACC stimulation can also elicit physiological effects, such as changes in pulse rate, blood pressure, and skin conductance (Pool and Ransohoff, 1949; Talairach et al., 1973; Mangina and Beuzeron-Mangina, 1996; Parvizi et al., 2013). A wide variety of other effects have been reported, including digestive sensations (Mulak et al., 2008), vestibular hallucinations (Kahane et al., 2003), anxiety and physical pain (Kahane et al., 2003; Mulak et al., 2008), and in the pregenual ACC, fear (Fox et al., 2020). It is worth noting that a variety of motor effects can also be elicited (Talairach et al., 1973; Lim et al., 1994; Selimbeyoglu and Parvizi, 2010), although these are not relevant to the present discussion.

In a recent study, Parvizi et al. (2013) applied iES to the anterior midcingulate cortex in 2 patients, producing complex, high-level effects on conscious experience. Stimulation in both patients elicited an intense feeling of perseverance in the face of an imminent challenge. For instance, Patient 1 provided the following analogy to explain the induced experience: "I started getting this feeling like ... I was driving into a storm." When asked if this was a negative experience, the patient responded "... it was more of a positive thing like ... push harder, push harder, push harder to try and get through this ...." Patient 2 also reported anticipating adversity but felt strongly that he would prevail and not give up, saying "I feel like ... I have to fight it, you know? I have to make it through." The consistent and striking alterations in experience produced in these 2 cases support a critical role for the ACC in emotional regulation and motivational states, and corroborate an early report that ACC stimulation elicited positive emotional effects and led to euphoric feelings (Talairach et al., 1973). Overall, these effects suggest that the ACC might play a local role in subserving certain conscious contents (i.e., emotional content) and therefore do not support higher-order or global workspace theories, nor, however, do they provide support for alternative theories suggesting a posterior "hot zone" substrate for consciousness (Koch et al., 2016; Koch, 2018).

Expanding on this work showing that iES of OFC and ACC can elicit profound effects on consciousness, Yih et al. (2019) explored whether the intensity of changes in conscious experience was linked to the magnitude of the electrical stimulation itself. First, they replicated prior work showing that ACC stimulation elicited changes primarily in the visceral and somatic domains, while stimulation to the OFC elicited changes chiefly in olfactory experience. However, this study also revealed a significant linear correlation between the magnitude of electrical 


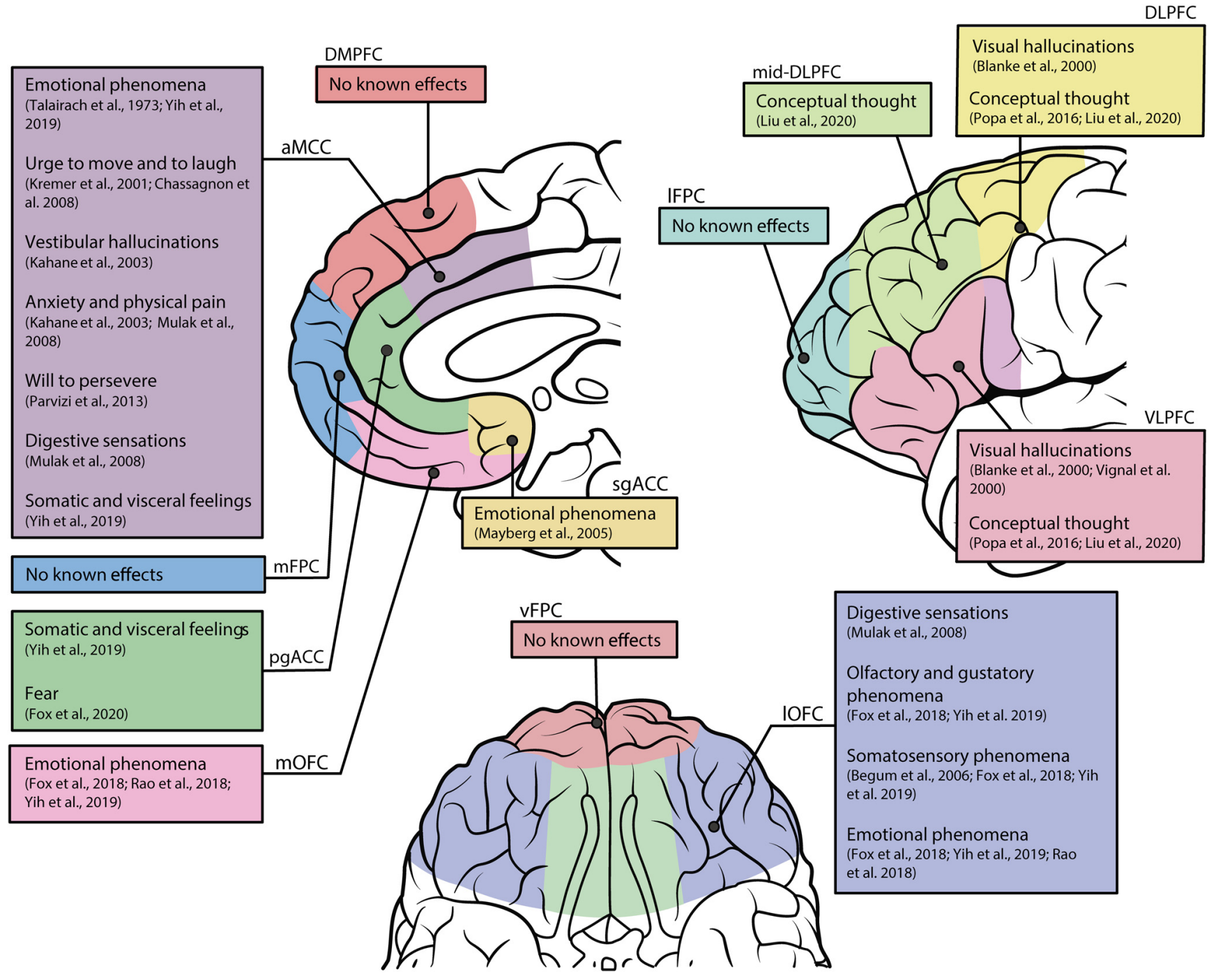

Figure 4. Summary of subjective effects following iES of the human PFC. A synthesis of subjective reports following iES to the medial (top left), lateral (top right), and ventral (bottom) portions of the human PFC. Arrows from text boxes point to the approximate stimulation sites. While reports have been accurately linked to specific PFC subregions, the placements are intended to be illustrative; locations are not exact. While this schematic provides a representative summary of the data, several cases which have not been replicated beyond a single subject are not included, although they are discussed in the main text. However, we include the case report by Vignal et al. (2000) given its relevance to the current debate. Detailed discussions of the subjective effects represented in this figure can be found in the original reports. sgACC, Subgenual ACC; pgACC, pregenual ACC; aMCC, anterior mid-cingulate cortex; IOFC, lateral OFC; mOFC, medial OFC; IFPC, lateral frontopolar cortex; mFPC, medial frontopolar cortex; vFPC, ventral frontopolar cortex; DMPFC, dorsomedial PFC.

stimulation (ranging from 2 to $8 \mathrm{~mA}$ ) in both the ACC and OFC and the subjective intensity of changes in conscious experience, especially for emotional phenomenology: that is, increasing the magnitude of stimulation elicited increasingly intense emotional experiences (Yih et al., 2019). This study reported compelling evidence that stimulation parameters directly affect the intensity of subjective effects elicited in prefrontal regions, providing strong support for the suitability of the iES method for probing the link between prefrontal regions and conscious experience.

Finally, an early study using deep brain stimulation (DBS) for treatment-resistant depression eported that $\mathrm{iES}$ of the subgenual ACC (BA 25) induced a variety of positive emotional experiences, including "connectedness" and "calmness," in 6 patients (Mayberg et al., 2005). Importantly, the stimulation parameters of DBS are not identical to those typically used in iES functional mapping sessions (although they are similar; see Box 1); moreover, a multicenter clinical trial of subgenual ACC DBS failed to replicate these positive emotional effects (Morishita et al., 2014).
Nonetheless, we include these effects here for the sake of completeness.

Overall then, while the heterogeneity of effects elicited in the OFC and ACC (Fig. 4) does not suggest a general role for these PFC regions in consciousness, these areas might nonetheless underlie emotional aspects of conscious experience (commonly referred to as emotional feelings) (LeDoux, 2020b). Our review of the extant data shows that stimulation of these regions elicits a variety of conscious changes in basic affective state and also complex emotional experience, which have been replicated across tens of patients in recent years (Selimbeyoglu and Parvizi, 2010; Parvizi et al., 2013; Fox et al., 2018b; Rao et al., 2018; Yih et al., 2019). Importantly, this evidence may provide support for recent accounts of higher-order theories of emotional consciousness (LeDoux and Brown, 2017; LeDoux, 2020a), which postulate that subcortical circuits generate unconscious emotional content that is then rendered conscious in cortical networks involved in "higher" cognitive processing. Although the ACC and OFC figure prominently in higher-order models of emotional 
consciousness, these regions are often proposed to interact with lateral prefrontal subregions to support emotional consciousness (LeDoux and Brown, 2017; LeDoux, 2020a), and the latter have yet to show changes in emotional experience following iES (Fig. 4).

\section{Conclusions and future directions}

In the ongoing debate over what role, if any, the PFC plays in consciousness, both sides have called for the use of causal methods to help clarify matters (Boly et al., 2017; Odegaard et al., 2017; Block, 2019). Here we explored findings from one of the best methods of causally investigating human brain function, synthesizing several decades of iES research undertaken in the PFC. Together, the extant iES literature suggests no general role for the PFC (especially its most anterior aspects) in conscious experience. Indeed, there is no part of the brain wherein iES is less likely to cause a noticeable change in consciousness than the most anterior regions of the PFC (Fox et al., 2020) (Figs. 2 and $3)$. However, the rare effects that are elicited are often complex, multimodal, and highly heterogeneous, including changes in perceptual phenomenology, thought processes, and emotional states. That said, reliable effects are largely confined to PFC regions such as the ACC or OFC (Fig. 4). Importantly, these are not the lateral $\mathrm{PFC}$ regions many theorists have in mind when they argue for an essential role for the PFC in consciousness. There are exceptions to this general trend, however, with some isolated case reports of thoughts (Popa et al., 2016; A. Liu et al., 2020) and visual hallucinations (Blanke et al., 2000; Vignal et al., 2000) elicited by iES of the more ventral and posterior portions of the lateral PFC (Fig. 4). But in hundreds of iES studies testing thousands of patients, comparable effects have never previously been reported, nor have they subsequently been replicated (Selimbeyoglu and Parvizi, 2010).

We therefore conclude that iES of lateral PFC regions does not reliably affect conscious experience, as might be predicted by most prefrontal theories of consciousness. This conclusion is largely consistent with previous reports that patients with even major lesions in the PFC show no apparent degradation in consciousness (Hebb and Penfield, 1940; Mettler, 1949; Brickner, 1952; Pollen, 1999). However, there have also been cases in which lateral prefrontal damage does appear to impair patients' ability to consciously interact with the environment (Barceló and Knight, 2002; Stuss and Knight, 2013), and what lesion findings tell us about the role of the PFC in consciousness remains intensively debated (Kozuch, 2014; Koch et al., 2016; Boly et al., 2017; Odegaard et al., 2017). It is also significant that the PFC is not the only region of the brain where iES-elicited effects are rare: other high-level association areas also appear to share this property (e.g., the posterior cingulate cortex) (Foster and Parvizi, 2017), and these trends appear to be driven by the brain's intrinsic network architecture (Fox et al., 2020). Low rates of iES effects are not unique to prefrontal regions, but appear to be a more general property of brain areas involved in abstract thought and complex cognitive function, although the lowest elicitation rates are nonetheless found in the anterior PFC (Fox et al., 2020; Koch, 2020).

In any case, the PFC comprises many subregions (Fig. 2), and various models of the PFC and consciousness often propose prominent roles for areas other than the lateral PFC (Dehaene and Changeux, 2011; Brown et al., 2019; Mashour et al., 2020). As we have shown, relatively rare, but nonetheless reliable, effects can be elicited from such regions, including the ACC (Talairach et al., 1973; Parvizi et al., 2013; Yih et al., 2019) and OFC (Fox et al., 2018b, 2020; Yih et al., 2019). While the specificity of the effects in the OFC and ACC does not suggest a general role for these regions in consciousness, stimulation of these regions does result in reproducible changes in emotional experience and may provide support for recent accounts of higher-order theories of emotional consciousness (LeDoux and Brown, 2017; LeDoux, 2020a). That said, the specific nature of most effects (whether visceral, somatic, olfactory, or emotional), as well as the lack of effects on ongoing perception, contradicts the notion that the $\mathrm{PFC}$ has a general role in rendering existing perceptual representations conscious.

Notably, patients might also be mind-wandering during a given iES trial; if attention is focused on internal thoughts rather than perceptual inputs, and if iES perturbs those thoughts, the patients might not report those perturbations. Indeed, if subjects are mind-wandering, they may not notice perturbations in ongoing perceptual experience. On balance, however, stimulation in the OFC and ACC tends to elicit phenomenal experiences that are seemingly unrelated to ongoing sensory processing (i.e., effects that can be considered hallucinations in the technical sense). Importantly, the opposite is often the case outside of the PFC. For example, stimulation of the fusiform gyrus produces distortions of face perception, which are almost exclusively tied to ongoing percepts, such as alterations in the facial features of clinical staff (Parvizi et al., 2012; Rangarajan et al., 2014; Keller et al., 2017; Schrouff et al., 2020).

Ultimately, this literature raises the critical question of the underlying mechanistic reason(s) that stimulation of certain areas elicits changes in conscious experience, whereas stimulation of others does not (e.g., intrinsic/extrinsic connectivity, cell types, time courses, informational coding schemes, and so on). Our prior work has shown that simple neurophysiological attributes, such as myelin concentration or electrical excitability, are unable to explain elicitation rates across the cortical mantle (Fox et al., 2020). One possible explanation lies in the specific tuning and encoding properties of single neurons throughout the cortex. Individual PFC neurons can be tuned to many higher-order features of perception, action, and intention, whereas neurons in unimodal regions tend to be tuned toward highly specific perceptual features (e.g., edge-selective neurons in V1) (Fusi et al., 2016; Parthasarathy et al., 2017). Further, neural coding schemes in the PFC are denser relative to the sparse codes found in perceptual areas (Duncan, 2001; Stokes et al., 2013). Therefore, PFC neurons are thought to represent information across larger circuits; hence, the localized nature of iES might result in lower rates of effect elicitation compared with unimodal regions where contiguous neuronal populations code for specific perceptual features (Fox et al., 2020). Even so, we expect that the disruptive nature of iES should cause some perturbations in denser circuits (as observed in the ACC and OFC, for instance) and, under higher-order and global workspace theories, perturb ongoing perceptual experience.

One major caveat is that iES to the PFC might still be influencing consciousness, but in subtle ways not noticeable or reportable by patients (Fox et al., 2020). Subtle effects on patients' behavior or task performance that are not reported in the paradigms used here could nonetheless be tested in future work applying iES during experimental tasks. Such work would be particularly valuable in evaluating iES effects in light of studies showing that both noninvasive transcranial brain stimulation (Rounis et al., 2010) and lesions (Marinkovic et al., 2000; Del Cul et al., 2009; Fleming et al., 2014; Colas et al., 2019) of the lateral PFC impair perceptual abilities under controlled task conditions. Additionally, more systematic and targeted iES research, with 
more elaborate and structured reports following each stimulation, would provide much needed information. Typically, iES research is undertaken in an opportunistic manner, with research goals subordinate to clinically relevant functional mapping, but lengthier and more systematic sessions are well within the bounds of ethical research and clinical constraints. In-depth efforts of this kind focused on the PFC might help to further inform the current debate and might replicate the rare findings reported to date (Blanke et al., 2000; Vignal et al., 2000; Vaca et al., 2011; Popa et al., 2016; A. Liu et al., 2020).

Of course, the results of iES studies alone cannot resolve this debate. Moreover, we hasten to reiterate both the limitations and limited understanding of the iES methodology (Box 1). Nonetheless, the iES method provides one of the most direct windows into human conscious experience. We believe that the extant iES findings present a challenge to higher-order and global workspace views, which suggest that conscious contents are represented in the PFC based on largely correlative evidence. We hope that the research outlined here can help to both inform and refine theoretical accounts of the PFC's clearly complex role in human consciousness.

\section{References}

Arroyo S, Lesser RP, Gordon B, Uematsu S, Hart J, Schwerdt P, Andreasson K, Fisher RS (1993) Mirth, laughter and gelastic seizures. Brain 116:757780 .

Baars BJ (1993) A cognitive theory of consciousness. Cambridge, MA: Cambridge UP.

Bancaud J, Talairach J (1992) Clinical semiology of frontal lobe seizures. Adv Neurol 57:3-58.

Barceló F, Knight RT (2002) Both random and perseverative errors underlie WCST deficits in prefrontal patients. Neuropsychologia 40:349-356.

Baylis L, Rolls E, Baylis G (1995) Afferent connections of the caudolateral orbitofrontal cortex taste area of the primate. Neuroscience 64:801-812.

Begum T, Ikeda A, Matsuhashi M, Mikuni N, Miyamoto S, Hashimoto N, Nagamine T, Fukuyama H, Shibasaki H (2006) Ipsilateral facial sensory and motor responses to basal fronto-temporal cortical stimulation: evidence suggesting direct activation of cranial nerves. Epilepsy Res 71:216222.

Billeke P, Ossandon T, Stockle M, Perrone-Bertolotti M, Kahane P, Lachaux JP, Fuentealba P (2017) Brain state-dependent recruitment of high-frequency oscillations in the human hippocampus. Cortex 94:87-99.

Blanke O, Landis T, Seeck M (2000) Electrical cortical stimulation of the human prefrontal cortex evokes complex visual hallucinations. Epilepsy Behav 1:356-361.

Blanke O, Ortigue S, Landis T, Seeck M (2002) Stimulating illusory ownbody perceptions. Nature 419:269-270.

Block N (1995) On a confusion about a function of consciousness. Behav Brain Sci 18:227-247.

Block N (2019) What is wrong with the no-report paradigm and how to fix it. Trends Cogn Sci 23:1003-1013.

Block N (2020). Finessing the bored monkey problem. Trends Cogn Sci 24:167-168.

Boly M, Balteau E, Schnakers C, Degueldre C, Moonen G, Luxen A, Phillips C, Peigneux P, Maquet P, Laureys S (2007) Baseline brain activity fluctuations predict somatosensory perception in humans. Proc Natl Acad Sci USA 104:12187-12192.

Boly M, Massimini M, Tsuchiya N, Postle BR, Koch C, Tononi G (2017) Are the neural correlates of consciousness in the front or in the back of the cerebral cortex? Clinical and neuroimaging evidence. J Neurosci 37:9603-9613.

Borchers S, Himmelbach M, Logothetis N, Karnath HO (2012) Direct electrical stimulation of human cortex: the gold standard for mapping brain functions? Nat Rev Neurosci 13:63.

Bosking WH, Sun P, Ozker M, Pei X, Foster BL, Beauchamp MS, Yoshor D (2017) Saturation in phosphene size with increasing current levels delivered to human visual cortex. J Neurosci 37:7188-7197.
Bosking WH, Foster B, Sun P, Beauchamp MS, Yoshor D (2018) Rules governing perception of multiple phosphenes by human observers. bioRxiv 302547.

Breitmeyer B, Ogmen H, Öğmen H (2006) Visual masking: time slices through conscious and unconscious vision. Oxford: Oxford UP.

Brickner RM (1952) Brain of patient A after bilateral frontal lobectomy: status of frontal-lobe problem. AMA Arch Neurol Psychiatry 68:293-313.

Brown R (2015) The HOROR theory of phenomenal consciousness. Philos Stud 172:1783-1794.

Brown R, Lau H, LeDoux JE (2019) Understanding the higher-order approach to consciousness. Trends Cogn Sci 23:754-768.

Bush G, Vogt BA, Holmes J, Dale AM, Greve D, Jenike MA, Rosen BR (2002) Dorsal anterior cingulate cortex: a role in reward-based decision making. Proc Natl Acad Sci USA 99:523-528.

Carlén M (2017) What constitutes the prefrontal cortex? Science 358:478482.

Cavada C, Compañy T, Tejedor J, Cruz-Rizzolo RJ, Reinoso-Suárez F (2000) The anatomical connections of the macaque monkey orbitofrontal cortex: a review. Cereb Cortex 10:220-242.

Chalmers DJ (1996) The conscious mind: in search of a fundamental theory. Oxford: Oxford UP.

Chalmers DJ (2000) What is a neural correlate of consciousness? In: Neural correlates of consciousness: Empirical and conceptual issues (Metzinger T ed) pp 17-40 Cambridge, MA:MIT Press.

Chassagnon S, Minotti L, Kremer S, Hoffmann D, Kahane P (2008) Somatosensory, motor, and reaching/grasping responses to direct electrical stimulation of the human cingulate motor areas. J Neurosurg 109:593-604.

Chauvel P, Kliemann F, Vignal JP, Chodkiewicz JP, Talairach J, Bancaud J (1995) The clinical signs and symptoms of frontal lobe seizures: phenomenology and classification. Adv Neurol 66:115-125; discussion 125-116.

Cleeremans A, Achoui D, Beauny A, Keuninckx L, Martin JR, MuñozMoldes S, Vuillaume L, de Heering A (2020) Learning to be conscious. Trends Cogn Sci 24:112-123.

Colas I, Chica AB, Rodenas E, Busquier H, Olivares G, Triviño M (2019) Conscious perception in patients with prefrontal damage. Neuropsychologia 129:284-293.

Crick F, Koch C (1990) Towards a neurobiological theory of consciousness. Paper presented at the Seminars in the Neurosciences.

Curot J, Busigny T, Valton L, Denuelle M, Vignal JP, Maillard L, Chauvel P, Pariente J, Trebuchon A, Bartolomei F, Barbeau EJ (2017) Memory scrutinized through electrical brain stimulation: a review of 80 years of experiential phenomena. Neurosci Biobehav Rev 78:161-177.

Dehaene S (2014) Consciousness and the brain: deciphering how the brain codes our thoughts. New York: Viking.

Dehaene S, Changeux JP (2011) Experimental and theoretical approaches to conscious processing. Neuron 70:200-227.

Dehaene S, Naccache L, Cohen L, Le Bihan D, Mangin JF, Poline JB, Rivière D (2001) Cerebral mechanisms of word masking and unconscious repetition priming. Nat Neurosci 4:752-758.

Del Cul A, Dehaene S, Reyes P, Bravo E, Slachevsky A (2009) Causal role of prefrontal cortex in the threshold for access to consciousness. Brain 132:2531-2540.

Desmurget M, Reilly KT, Richard N, Szathmari A, Mottolese C, Sirigu A (2009) Movement intention after parietal cortex stimulation in humans. Science 324:811-813.

Desmurget M, Song Z, Mottolese C, Sirigu A (2013) Re-establishing the merits of electrical brain stimulation. Trends Cogn Sci 17:442-449.

Devinsky O, Morrell MJ, Vogt BA (1995) Contributions of anterior cingulate cortex to behaviour. Brain 118:279-306.

Dixon ML, Thiruchselvam R, Todd R, Christoff K (2017) Emotion and the prefrontal cortex: an integrative review. Psychol Bull 143:1033-1081.

Dunbar K, Sussman D (1995) Toward a cognitive account of frontal lobe function: simulating frontal lobe deficits in normal subjects. Ann NY Acad Sci 769:289-304.

Duncan J (2001) An adaptive coding model of neural function in prefrontal cortex. Nat Rev Neurosci 2:820-829.

Feindel W, Penfield W (1954) Localization of discharge in temporal lobe automatism. AMA Arch Neurol Psychiatry 72:605-630.

Fleming SM, Ryu J, Golfinos JG, Blackmon KE (2014) Domain-specific impairment in metacognitive accuracy following anterior prefrontal lesions. Brain 137:2811-2822. 
Foster BL, Parvizi J (2017) Direct cortical stimulation of human posteromedial cortex. Neurology 88:685-691.

Fox KC, Parvizi J (2021) Fidelity of first-person reports following intracranial neuromodulation of the human brain: an empirical assessment of sham stimulation in neurosurgical patients. Brain Stimul 14:77-79.

Fox KC, Foster BL, Kucyi A, Daitch AL, Parvizi J (2018a) Intracranial electrophysiology of the human default network. Trends Cogn Sci 22:307-324.

Fox KC, Yih J, Raccah O, Pendekanti SL, Limbach LE, Maydan DD, Parvizi J (2018b) Changes in subjective experience elicited by direct stimulation of the human orbitofrontal cortex. Neurology 91:e1519-e1527.

Fox KC, Shi L, Baek S, Raccah O, Foster BL, Saha S, Margulies DS, Kucyi A, Parvizi J (2020) Intrinsic network architecture predicts the effects elicited by intracranial electrical stimulation of the human brain. Nat Hum Behav 4:1039-1052.

Fried I, Wilson CL, MacDonald KA, Behnke EJ (1998) Electric current stimulates laughter. Nature 391:650.

Fusi S, Miller EK, Rigotti M (2016) Why neurons mix: high dimensionality for higher cognition. Curr Opin Neurobiol 37:66-74.

Gordon B, Lesser RP, Rance NE, Hart J Jr, Webber R, Uematsu S, Fisher RS (1990) Parameters for direct cortical electrical stimulation in the human: histopathologic confirmation. Electroencephalogr Clin Neurophysiol 75:371-377.

Gross J, Schmitz F, Schnitzler I, Kessler K, Shapiro K, Hommel B, Schnitzler A (2004) Modulation of long-range neural synchrony reflects temporal limitations of visual attention in humans. Proc Natl Acad Sci USA 101:13050-13055.

Hebb DO, Penfield W (1940) Human behavior after extensive bilateral removal from the frontal lobes. Arch Neurol Psychiatry 44:421-438.

Henri-Bhargava A, Stuss DT, Freedman M (2018) Clinical assessment of prefrontal lobe functions. Continuum (Minneap Minn) 24:704-726.

Inman CS, Bijanki KR, Bass DI, Gross RE, Hamann S, Willie JT (2018) Human amygdala stimulation effects on emotion physiology and emotional experience. Neuropsychologia 145:106722.

Jack AI, Shallice T (2001) Introspective physicalism as an approach to the science of consciousness. Cognition 79:161-196.

Kahane P, Hoffmann D, Minotti L, Berthoz A (2003) Reappraisal of the human vestibular cortex by cortical electrical stimulation study. Ann Neurol 54:615-624.

Kapoor V, Dwarakanath A, Safavi S, Werner J, Nicholas H, Logothetis N, Panagiotaropoulos T (2018) Spiking activity in the prefrontal cortex reflects spontaneous perceptual transitions during a no report binocular rivalry paradigm. Paper presented at the 11th FENS Forum of Neuroscience.

Kapoor V, Dwarakanath A, Safavi S, Werner J, Panagiotaropoulos T, Logothetis N (2019) Neuronal discharges in the prefrontal cortex reflect changes in conscious perception during a no report binocular rivalry paradigm. In 23rd Annual Meeting of the Association for the Scientific Study of Consciousness (ASSC 23).

Kapoor V, Dwarakanath A, Safavi S, Werner J, Besserve M, Panagiotaropoulos TI, Logothetis NK (2020) Decoding the contents of consciousness from prefrontal ensembles. bioRxiv. doi: 10.1101/ 2020.01.28.921841.

Keller CJ, Davidesco I, Megevand P, Lado FA, Malach R, Mehta AD (2017) Tuning face perception with electrical stimulation of the fusiform gyrus. Hum Brain Mapp 38:2830-2842.

Ketzef M, Kahn J, Weissberg I, Becker A, Friedman A, Gitler D (2011) Compensatory network alterations upon onset of epilepsy in synapsin triple knock-out mice. Neuroscience 189:108-122.

Kim CY, Blake R (2005) Psychophysical magic: rendering the visible "invisible." Trends Cogn Sci 9:381-388.

Koch C (2018) What is consciousness? Nature 557:S8-S12.

Koch C (2019) The feeling of life itself: why consciousness is widespread but can't be computed. Cambridge, MA: Massachusetts Institute of Technology.

Koch C (2020) Hot or not. Nat Hum Behav 4:991-992.

Koch C, Massimini M, Boly M, Tononi G (2016) Neural correlates of consciousness: progress and problems. Nat Rev Neurosci 17:307-321.

Kozuch B (2014) Prefrontal lesion evidence against higher-order theories of consciousness. Philos Stud 167:721-746.

Kremer S, Chassagnon S, Hoffmann D, Benabid A, Kahane P (2001) The cingulate hidden hand. J Neurol Neurosurg Psychiatry 70:264-265.
Kringelbach ML, Rolls ET (2004) The functional neuroanatomy of the human orbitofrontal cortex: evidence from neuroimaging and neuropsychology. Prog Neurobiol 72:341-372.

Lamme V (2014) The crack of dawn: perceptual functions and neural mechanisms that mark the transition from unconscious processing to conscious vision: Open MIND. Frankfurt am Main: MIND Group.

Lane RD, Reiman EM, Axelrod B, Yun LS, Holmes A, Schwartz GE (1998) Neural correlates of levels of emotional awareness: evidence of an interaction between emotion and attention in the anterior cingulate cortex. J Cogn Neurosci 10:525-535.

Lau H (2019) Consciousness, metacognition, and perceptual reality monitoring. PsyArXiv

Lau H, Passingham RE (2006) Relative blindsight in normal observers and the neural correlate of visual consciousness. Proc Natl Acad Sci USA 103:18763-18768

Lau H, Rosenthal D (2011) Empirical support for higher-order theories of conscious awareness. Trends Cogn Sci 15:365-373.

LeDoux JE (2020a) How does the non-conscious become conscious? Curr Biol 30:R196-R199.

LeDoux JE (2020b) Thoughtful feelings. Curr Biol 30:R619-R623.

LeDoux JE, Brown R (2017) A higher-order theory of emotional consciousness. Proc Natl Acad Sci USA 114:E2016-E2025.

Lim SH, Dinner DS, Pillay PK, Lüders H, Morris HH, Klem G, Wyllie E, Awad IA (1994) Functional anatomy of the human supplementary sensorimotor area: results of extraoperative electrical stimulation. Electroencephalogr Clin Neurophysiol 91:179-193.

Liu A, Friedman D, Barron DS, Wang X, Thesen T, Dugan P (2020) Forced conceptual thought induced by electrical stimulation of the left prefrontal gyrus involves widespread neural networks. Epilepsy Behav 104:106644.

Liu S, Parvizi J (2019) Cognitive refractory state caused by spontaneous epileptic high-frequency oscillations in the human brain. Sci Transl Med 11: eaax7830.

Mahl GF, Rothenberg A, Delgado JM, Hamlin H (1964) Psychological responses in the human to intracerebral electrical stimulation. Psychosom Med 26:337-368.

Manfioli V, Saladini M, Cagnin A (2013) Ictal visual hallucinations due to frontal lobe epilepsy in a patient with bipolar disorder. Epilepsy Behav Case Rep 1:146-149.

Mangina CA, Beuzeron-Mangina JH (1996) Direct electrical stimulation of specific human brain structures and bilateral electrodermal activity. Int J Psychophysiol 22:1-8.

Marinkovic K, Trebon P, Chauvel P, Halgren E (2000) Localised face processing by the human prefrontal cortex: face-selective intracerebral potentials and post-lesion deficits. Cogn Neuropsychol 17:187-199.

Mashour GA, Roelfsema P, Changeux JP, Dehaene S (2020) Conscious processing and the global neuronal workspace hypothesis. Neuron 105:776798.

Mayberg HS, Lozano AM, Voon V, McNeely HE, Seminowicz D, Hamani C, Schwalb JM, Kennedy SH (2005) Deep brain stimulation for treatmentresistant depression. Neuron 45:651-660.

Mazzola L, Isnard J, Peyron R, Mauguière F (2012) Stimulation of the human cortex and the experience of pain: Wilder Penfield's observations revisited. Brain 135:631-640.

Mendez MF, Cherrier MM, Perryman KM (1996) Epileptic forced thinking from left frontal lesions. Neurology 47:79-83.

Mettler FA (1949) Selective partial ablation of the frontal cortex, a correlative study of its effects on human psychotic subjects. New York: Hoeber.

Michel M, Morales J (2020) Minority reports: Consciousness and the prefrontal cortex. Mind \& Language 35:493-513.

Miller EK, Cohen JD (2001) An integrative theory of prefrontal cortex function. Annu Rev Neurosci 24:167-202.

Moore CI, Cao R (2008) The hemo-neural hypothesis: on the role of blood flow in information processing. J Neurophysiol 99:2035-2047.

Mohan UR, Watrous AJ, Miller JF, Lega BC, Sperling MR, Worrell GA, Gross RE, Zaghloul KA, Jobst BC, Davis KA, Sheth SA, Stein JM, Das SR, Gorniak R, Wanda PA, Rizzuto DS, Kahana MJ, Jacobs J (2020) The effects of direct brain stimulation in humans depend on frequency, amplitude, and white-matter proximity. Brain Stimul 13:1183-1195.

Mole JP, Subramanian L, Bracht T, Morris H, Metzler-Baddeley C, Linden DE (2016) Increased fractional anisotropy in the motor tracts of Parkinson's disease suggests compensatory neuroplasticity or selective neurodegeneration. Eur Radiol 26:3327-3335. 
Morishita T, Fayad SM, Higuchi MA, Nestor KA, Foote KD (2014) Deep brain stimulation for treatment-resistant depression: systematic review of clinical outcomes. Neurotherapeutics 11:475-484.

Mulak A, Kahane P, Hoffmann D, Minotti L, Bonaz B (2008) Brain mapping of digestive sensations elicited by cortical electrical stimulations. Neurogastroenterol Motil 20:588-596.

Mullan S, Penfield W (1959) Illusions of comparative interpretation and emotion: production by epileptic discharge and by electrical stimulation in the temporal cortex. AMA Arch Neurol Psychiatry 81:269-284.

Nagel T (1974) What is it like to be a bat? Philos Rev 83:435-450.

Nichols AL, Maner JK (2008) The good-subject effect: investigating participant demand characteristics. J Gen Psychol 135:151-166.

Northoff G, Heinzel A, De Greck M, Bermpohl F, Dobrowolny H, Panksepp $J$ (2006) Self-referential processing in our brain: a meta-analysis of imaging studies on the self. Neuroimage 31:440-457.

Odegaard B, Knight RT, Lau H (2017) Should a few null findings falsify prefrontal theories of conscious perception? J Neurosci 37:9593-9602.

Panagiotaropoulos TI, Deco G, Kapoor V, Logothetis NK (2012) Neuronal discharges and gamma oscillations explicitly reflect visual consciousness in the lateral prefrontal cortex. Neuron 74:924-935.

Panagiotaropoulos TI, Dwarakanath A, Kapoor V (2020) Prefrontal cortex and consciousness: beware of the signals. Trends Cogn Sci 24:343-344.

Parthasarathy A, Herikstad R, Bong JH, Medina FS, Libedinsky C, Yen SC (2017) Mixed selectivity morphs population codes in prefrontal cortex. Nat Neurosci 20:1770-1779.

Parvizi J, Kastner S (2018) Promises and limitations of human intracranial electroencephalography. Nat Neurosci 21:474-483.

Parvizi J, Jacques C, Foster BL, Withoft N, Rangarajan V, Weiner KS, GrillSpector K (2012) Electrical stimulation of human fusiform face-selective regions distorts face perception. J Neurosci 32:14915-14920.

Parvizi J, Rangarajan V, Shirer WR, Desai N, Greicius MD (2013) The will to persevere induced by electrical stimulation of the human cingulate gyrus. Neuron 80:1359-1367.

Penfield W (1958) Some mechanisms of consciousness discovered during electrical stimulation of the brain. Proc Natl Acad Sci USA 44:51-66.

Penfield W (1972) The electrode, the brain and the mind. Z Neurol 201:297309.

Penfield W, Boldrey E (1937) Somatic motor and sensory representation in the cerebral cortex of man as studied by electrical stimulation. Brain 60:389-443.

Penfield W, Perot P (1963) The brain's record of auditory and visual experience: a final summary and discussion. Brain 86:595-696.

Pollen DA (1999) On the neural correlates of visual perception. Cereb Cortex 9:4-19.

Pool JL, Ransohoff J (1949) Autonomic effects on stimulating rostral portion of cingulate gyri in man. J Neurophysiol 12:385-392.

Popa I, Donos C, Barborica A, Opris I, Mălîia MD, Ene M, Ciurea J, Mîndrut ă I (2016) Intrusive thoughts elicited by direct electrical stimulation during stereo-electroencephalography. Front Neurol 7:114.

Rangarajan V, Hermes D, Foster BL, Weiner KS, Jacques C, Grill-Spector K, Parvizi J (2014) Electrical stimulation of the left and right human fusiform gyrus causes different effects in conscious face perception. J Neurosci 34:12828-12836.

Rao VR, Sellers KK, Wallace DL, Lee MB, Bijanzadeh M, Sani OG, Yang Y, Shanechi MM, Dawes HE, Chang EF (2018) Direct electrical stimulation of lateral orbitofrontal cortex acutely improves mood in individuals with symptoms of depression. Curr Biol 28:3893-3902.e3894.

Rattay F (1999) The basic mechanism for the electrical stimulation of the nervous system. Neuroscience 89:335-346.

Rosenthal D (2011) Exaggerated reports: reply to Block. Analysis 71:431-437.

Rounis E, Maniscalco B, Rothwell JC, Passingham RE, Lau H (2010) Thetaburst transcranial magnetic stimulation to the prefrontal cortex impairs metacognitive visual awareness. Cogn Neurosci 1:165-175.

Sadaghiani S, Hesselmann G, Kleinschmidt A (2009) Distributed and antagonistic contributions of ongoing activity fluctuations to auditory stimulus detection. J Neurosci 29:13410-13417.
Safavi S, Kapoor V, Logothetis NK, Panagiotaropoulos TI (2014) Is the frontal lobe involved in conscious perception? Front Psychol 5:1063.

Satow T, Usui K, Matsuhashi M, Yamamoto J, Begum T, Shibasaki H, Ikeda A, Mikuni N, Miyamoto S, Hashimoto N (2003) Mirth and laughter arising from human temporal cortex. J Neurol Neurosurg Psychiatry 74:1004-1005.

Schrouff J, Raccah O, Baek S, Rangarajan V, Salehi S, Mourão-Miranda J, Helili Z, Daitch AL, Parvizi J (2020) Fast temporal dynamics and causal relevance of face processing in the human temporal cortex. Nat Commun 11:1-13.

Selimbeyoglu A, Parvizi J (2010) Electrical stimulation of the human brain: perceptual and behavioral phenomena reported in the old and new literature. Front Hum Neurosci 4:46.

Sergent C, Baillet S, Dehaene S (2005) Timing of the brain events underlying access to consciousness during the attentional blink. Nat Neurosci 8:1391-1400.

Silvanto J, Cowey A, Lavie N, Walsh V (2005) Striate cortex (V1) activity gates awareness of motion. Nat Neurosci 8:143-144.

Sperli F, Spinelli L, Pollo C, Seeck M (2006) Contralateral smile and laughter, but no mirth, induced by electrical stimulation of the cingulate cortex. Epilepsia 47:440-443.

Stokes MG, Kusunoki M, Sigala N, Nili H, Gaffan D, Duncan J (2013) Dynamic coding for cognitive control in prefrontal cortex. Neuron 78:364-375.

Stuss DT, Knight RT (2013) Principles of frontal lobe function. Oxford: Oxford UP.

Sutula TP (2004) Mechanisms of epilepsy progression: current theories and perspectives from neuroplasticity in adulthood and development. Epilepsy Res 60:161-171.

Talairach J, Bancaud J, Geier S, Bordas-Ferrer M, Bonis A, Szikla G, Rusu M (1973) The cingulate gyrus and human behaviour. Electroencephalogr Clin Neurophysiol 34:45-52.

Tehovnik E, Tolias A, Sultan F, Slocum W, Logothetis N (2006) Direct and indirect activation of cortical neurons by electrical microstimulation. J Neurophysiol 96:512-521.

Tononi G, Boly M, Massimini M, Koch C (2016) Integrated information theory: from consciousness to its physical substrate. Nat Rev Neurosci 17:450-461.

Trevisi G, Eickhoff SB, Chowdhury F, Jha A, Rodionov R, Nowell M, Miserocchi A, McEvoy AW, Nachev P, Diehl B (2018) Probabilistic electrical stimulation mapping of human medial frontal cortex. Cortex 109:336-346.

Tsuchiya N, Koch C (2005) Continuous flash suppression reduces negative afterimages. Nat Neurosci 8:1096-1101.

Vaca GF, Lüders HO, Basha MM, Miller JP (2011) Mirth and laughter elicited during brain stimulation. Epileptic Disord 13:435-440.

Van Gaal S, Lamme VA, Fahrenfort JJ, Ridderinkhof KR (2011) Dissociable brain mechanisms underlying the conscious and unconscious control of behavior. J Cogn Neurosci 23:91-105.

Vignal J, Chauvel P, Halgren E (2000) Localised face processing by the human prefrontal cortex: stimulation-evoked hallucinations of faces. Cogn Neuropsychol 17:281-291.

Winawer J, Parvizi J (2016) Linking electrical stimulation of human primary visual cortex, size of affected cortical area, neuronal responses, and subjective experience. Neuron 92:1213-1219.

Yang E, Brascamp J, Kang MS, Blake R (2014) On the use of continuous flash suppression for the study of visual processing outside of awareness. Front Psychol 5:724.

Yeo BT, Krienen FM, Sepulcre J, Sabuncu MR, Lashkari D, Hollinshead M, Roffman JL, Smoller JW, Zöllei L, Polimeni JR, Fischl B, Liu H, Buckner RL (2011) The organization of the human cerebral cortex estimated by intrinsic functional connectivity. J Neurophysiol 106:1125-1165.

Yih J, Beam DE, Fox KC, Parvizi J (2019) Intensity of affective experience is modulated by magnitude of intracranial electrical stimulation in human orbitofrontal, cingulate and insular cortices. Soc Cogn Affect Neurosci $14: 339-351$ 